\title{
Não luta comigo, não é meu amigo! A luta como política tupi guarani
}

\author{
Amanda Cristina Danaga ${ }^{1}$ \\ Universidade Federal de São Carlos
}

Resumo: Luta é um termo que aparece com bastante frequência quando se trata das reflexões que envolvem relações e discursos ameríndios. Neste texto, pretendo considerar como os Tupi Guarani, em especial os da Ywyty Guaçu ou aldeia Renascer (Ubatuba-SP), operam com seus modos específicos de fazer políticas e atentar para os enunciados dessas políticas, onde luta aparece como um conceito fundamental. O que querem dizer os Tupi Guarani ao afirmarem estamos na luta? Minha proposta incide em uma tentativa de tradução, não de modo literal, já que se trata de um termo proferido em português, porém de sentido, ao buscar as acepções que o termo assume em um contexto etnográfico particular. A ideia aqui é lançar mão de um debate em torno da construção das possíveis interpretações antropológicas, por meio dos dados etnográficos, da noção de luta.

Palavras-Chave: Luta; Políticas; Tupi Guarani. 


\title{
Do not fight me, you are not my friend! The fight like politics tupi guarani
}

\begin{abstract}
Fight is a term that appears more frequently when it comes to reflections involving Amerindian discourse and relations. This text, pretending to have the Tupi Guarani, in particular on the Ywyty Guaçu or village Renascer (Ubatuba-SP), operate with their extrinsic ways of making and presenting public policies, where fight appears as a fundamental concept. What does the Tupi Guarani say when we say we are in the fight? My proposal focuses on an attempt to translate, not in a literal way, since it is a term rendered in Portuguese, although meaningful, in seeking the perceptions that the term assumes in a particular ethnographic context. An idea here is the hand of a debate on the subject from the perspective of anthropological interventions, through ethnographic data, of the notion of fight.
\end{abstract}

Keywords: Fight; Policies; Tupi Guarani.

\section{¿No lucha conmigo, no es mi amigo! La lucha como política tupí guaraní}

\begin{abstract}
Resumen: Lucha es un término que aparece con bastante frecuencia cuando se trata de las reflexiones que envuelven relaciones y discursos amerindios. En este texto, pretendo considerar como los Tupi Guaraní, en especial los de Ywyty Guaçu o pueblo Renascer (Ubatuba-SP), operan con sus modos específicos de hacer políticas y atentar a los enunciados de esas políticas, donde lucha aparece como un concepto fundamental. ¿Qué quiere decir los Tupí Guaraní al afirmar que estamos en la lucha? Mi propuesta aborda en un intento de traducir, no literalmente, ya que es un término que se da en portugués, pero en un sentido, a buscar los significados asignados al término lleva en un contexto etnográfico particular. La idea aquí es lanzar un debate en torno a la construcción de las posibles interpretaciones antropológicas, por medio de los datos etnográficos, de la noción de lucha.
\end{abstract}

Palabras clave: Lucha; Políticas; Tupi Guaraní. 


\title{
O português dos indígenas
}

\begin{abstract}
A final, toda tradução é uma traição? E quando a tradução não é sobre a transposição de uma língua à outra, mas acontece na busca de sentido entre mundos e modos de pensar tão distintos? A questão da tradução esteve presente na antropologia como uma problemática clássica. O problema da tradução e a preocupação com a construção do texto etnográfico tangenciou os dilemas enfrentados pelos autores que ficaram conhecidos como pós-modernos que, dentre muitas reflexões, compararam a antropologia a uma espécie de escrita narrativa, uma disciplina em trânsito entre a ciência e a literatura. A escrita etnográfica tornou-se um desafio para aqueles que a enfrentam, concedendo às grafias grande importância sobre o modo como se dá a produção do conhecimento antropológico. A dificuldade foi posta para a antropologia ao tentar estabelecer uma correspondência entre as informações e conceitos ameríndios e a tradução destes. Por ser componente de mundos tão distintos, a busca de sentido para os dados etnográficos representava, em meio a esse debate, um desafio para antropólogos e antropólogas que tentavam decifrar seus dados à luz de suas próprias percepções.
\end{abstract}

A partir de um incontável número de equivocações e imprecisões analíticas (que por vezes ainda se repetem), a antropologia amadureceu para - ao invés de empenhar-se na interpretação, explicação, análise, exame, tradução ou contextualização - a possibilidade de realizar uma "experimentação com o pensamento ameríndio", tomando as ideias indígenas por conceitos, considerando-as em suas potencialidades filosóficas. "Realizar os possíveis nativos como virtualidades é o mesmo que tratar as ideias nativas como conceitos", propõe Viveiros de Castro (2002, p.132), estabelecendo uma equivalência de sentidos entre os discursos indígenas e as reflexões antropológicas.

Assim, entendida como um instrumento filosófico, a antropologia considera os discursos indígena e dos antropólogos menos como textos a serem lidos e mais como práticas de sentidos postas em relação, sem perder de vista que toda relação carrega em si mesma uma transformação. Aceitar as ideias indígenas como conceitos vai ao encontro de fazer da antropologia, conforme afirmou Tim Ingold, "uma filosofia com gente dentro".

Isto posto, o que pretendo aqui, é estender minhas reflexões para uma investigação sobre os entendimentos e os usos que fazem os Tupi Guarani da categoria conhecida, por nós, não indígenas, como "política". Proponho pensar modos de fazer política nas relações da Ywyty Guaçu, substantivamente, portanto, como uma possibilidade de tomar algo que existe e que chamamos de política, pelas muitas variáveis que esse termo pode assumir.

Inspirada em Clastres, que em "A Sociedade Contra o Estado" (2003) sinalizou para uma transformação no modo de compreensão da política indígena, Perrone-Moisés (2011) recomenda que busquemos os termos ameríndios de se conceber e de praticar a política, encaminhando para um entendimento do que seria uma filosofia política ameríndia. Seguindo o que fora sugerido pela antropologia política inaugurada em Clastres e discutido por tantos outros depois dele $^{2}$, o que pretendo é refletir a respeito da política à maneira ameríndia, a saber, como é vivida, conceituada e, sobretudo, enunciada entre os Tupi Guarani na 
Ywyty Guaçu. Ao que tudo indica, o que eu chamo de política, na Ywyty Guaçu, através das falas cotidianas - com ênfase nas da liderança - ganha outros nomes.

Sublinhei acima a ênfase voltada aos enunciados da liderança, na intenção de tornar aparente a relação entre a compreensão dos movimentos políticos a partir de suas próprias filosofias (ao procurar os termos ameríndios da política), com os regimes de subjetivação ameríndios. Há uma conexão entre a política ameríndia e a autobiografia, que vem sendo considerada no contexto da política indígena recente. ${ }^{3}$ Calavia Saez (2007) observa a evidência das lideranças indígenas que passaram a falar "pelos seus grupos", através da primeira pessoa do singular e por meio das narrativas de suas memórias pessoais. 4

Esse parece ser o caso de Antonio da Silva Awá, que conta sua trajetória não somente como atual liderança da Ywyty Guaçu, mas como um personagem influente no contexto do movimento indígena do litoral paulista. Ao falar de sua trajetória e de sua vida política, ele aciona demasiadamente a palavra luta. A que se refere Awá quando menciona o termo luta, sempre em português? Quais traduções os indígenas estão nos propondo em suas falas, sobretudo quando proferidas na nossa língua?

Perrone-Moises (2015), ao discorrer sobre a "festa" para os ameríndios, comenta que no Brasil os índios costumam traduzir por "festa" o que os antropólogos "retraduzem" como ritual. De acordo com a autora, há uma necessidade em levar a sério o que ela chamou de o "português dos índios", pois são várias as palavras usadas pelos indígenas que os etnólogos registram sem lhes dar muita atenção. Não gostaria de incorrer nesse erro ao falar sobre luta para os Tupi Guarani.

Julgo necessário mencionar que minha comunicação com os Tupi Guarani acontecia, sobretudo, em português. O que significa que nossos diálogos aconteciam em uma mesma língua, porém, eu não ousaria supor que em nossas conversas havia uma equivalência plena e mútua de compreensão. Havia, também ali, uma tentativa de tradução. Não precisamente de uma língua ou de um sistema de vocabulário e de sintaxe, mas de sistemas de pensamentos completamente distintos. Franchetto (2012), ao discorrer a respeito da tradução, afirma que tradução é movimento, é transformação, não somente de uma língua à outra, como de nexos culturais, mundos e contextos de enunciação.

No exercício penoso de equilibrar-se entre a literalidade e a interpretação, a tradução deve ser capaz de apontar, sobretudo, as potencialidades do original e de suas formas, às vezes escondidas, de poética. A tradução é perigosamente ativa; participa da construção de um nexo cultural. Transforma e revela. (FRANCHETTO, 2012, p. 54)

Um rápido olhar sobre os usos que os Tupi Guarani fazem do termo luta poderia sugerir que essa é uma definição clássica que faz parte do movimento indígena e que deriva de uma significação vinculada ao campo do direito, entretanto, como já disse Viveiros de Castro (2002), "nenhuma ideia interessante é evidente", pelo menos não no mundo ameríndio. Associar luta unicamente a uma forma de expressão do campo jurídico ou, ainda, entendê-la como um termo que tem por tradução - inserido na lógica do pensamento ameríndio - a guerra, limitaria as possibilidades de reflexão.

Tomar a política do modo como concebem os Tupi Guarani, vendo o que de fato é política para eles, como pensam e enunciam a política e como diferenciam os conceitos dentro da política é o que pretendo analisar para, posteriormente,

3 Verificar os trabalhos de Course; Oakdale (2014), Gonçalves (2012); Kofes (2001); Kofes; Manica (2015); Kopenawa; Albert (2015); Oakdale (2005; 2007); Saez (2006; 2007).

4 Dois grandes exemplos para o caso brasileiro são Davi Yanomami e Aílton Krenak, porém há muitos outros. 
relacionar com as noções de liderança na Ywyty Guaçu. 5 Nesse sentido, a primeira especificidade que notei foi que, um dos meus entendimentos para aquilo a que eu denominava pelo termo política, ou seja, relações que se davam com o Estado e demais setores do mundo dos não índios, os Tupi Guarani apontavam e enunciavam como luta. Mas não seria suficiente dizer que para os Tupi da Ywyty Guaçu, política é "como se fosse" luta. Fazer isso seria sobrepor a minha criatividade a dos Tupi Guarani, sem compreender a riqueza da dinâmica presente em sua socialidade (WAGNER, 2010).

A ideia de política como luta, entre os Tupi Guarani, conecta-se com o modo tradicional de se fazer política entre os Tupi-Guarani (agora com hífen), ou seja, através da guerra. Se o modo clássico Tupi de se fazer política é fazer guerra, é por isso que os Tupi Guarani lutam há tantos anos, como disse Awá: Nós, os Tupi, estamos se acabando, a gente está lutando faz 514 anos.

Quando eles dizem, estamos na luta, eles não estão simplesmente dizendo que a vida é dura, mas que a guerra é uma constante, que relacionar-se com os brancos faz da vida deles uma guerra sem fim e que essa é a política dos Tupi Guarani. Luta, portanto, não é um termo neutro ou transparente, mas um conceito ameríndio carregado de potência, uma potência que se cumpre na relação entre eles e os não índios, desde os tempos do “descobrimento". É preciso entender luta como conceito em relação. Na tentativa de melhor compreender o sentido do conceito ameríndio de luta, creio que seja imprescindível localizar onde tal conceito é manifestado, ou seja, ver como ele se realiza nas experiências ameríndias, no caso entre os Tupi Guarani, em suas falas e enunciados na Ywyty Guaçu e fora dela.

\section{Luta e liderança}

Na Ywyty Guaçu, o conceito de luta aparece quase sempre relacionado ao de liderança. É a liderança da aldeia quem organiza o pessoal para a luta, geralmente associada aos diálogos firmados junto aos juruá (não indígenas). Todavia, antes de adentrar na descrição etnográfica de um evento ocorrido na aldeia para o qual o termo luta foi enunciado como modo de compreensão do acontecido, dedicome a escrever um pouco a respeito da Ywyty Guaçu, a fim de facilitar o entendimento do leitor.

Mais conhecida pelo nome de aldeia Renascer, a Ywyty Guaçu fica localizada no município de Ubatuba, litoral norte do estado de São Paulo, no bairro do Corcovado. O bairro possui este nome justamente porque é lá que se encontra o Pico do Corcovado. A Ywyty Guaçu, que em Tupi Guarani significa morro grande, fica aos pés do morro. Na aldeia vivem famílias tupi guarani e famílias guarani mbya. Sua formação aconteceu ao longo dos anos de 1997 e 1998, durante o processo das gravações do longa metragem "Hans Staden”, do diretor Luis Alberto Pereira.

\footnotetext{
${ }^{5}$ Raras as vezes em que me deparei com o uso do termo política em campo, exceto para situações que remetiam a notícias de jornais que faziam referência ao que se passava em Brasília, ou em contextos municipais em ações na câmara dos vereadores e/ou na prefeitura. Ouvi também, uma vez, uma menção a política associada a ideia de conflito. Para esse caso, o termo remetia ao tipo particular da organização social tupi das aldeias, permeada por conflitos, segundo um intercolutor: "[...] dentro das próprias comunidades, existe sempre política, queira ou não queira existe sempre né, na minha aldeia mesmo [...] é assim, é histórico isso. Briga, sabe? Que acontece essas coisas dentro da aldeia. Sempre tem algum conflito, e coisa assim que você vai no Mbya e não vê isso [...] Até que eu considero muito mais essa coisa do tupi, por conta dessa semelhança que tem, em termos da cultura, do jeito de falar, das características, o modo político de organização dentro da comunidade é muito parecido, entendeu? Então a gente, inclusive, dos mbya a gente sofre preconceito por isso, porque eles são muito diferentes da gente, por que eles acham que a comunidade tupi, não sei, essa coisa mais de energia, de briga, e ser mais guerreiro, sempre estar mais nos conflitos, envolvidos nessa questão, é diferente deles, os Mbya são muito reservados, eles não entram nessa questão discutir e de brigar".
} 
Alguns indígenas da região, dentre eles Antonio Awá, foram convidados para trabalhar como figurantes no filme. A ocupação do espaço não foi imediatamente ao término das gravações, quando a área ficou esquecida.. A aldeia cenográfica ficou abandonada e o local vazio. Não houve a construção de um "centro cultural indígena”, conforme fora prometido aos indígenas e nem o desmanche do cenário. A família de Awá e as demais famílias que participaram da ocupação começaram a realizar frequentes encontros nas grandes ocas cenográficas e, posteriormente, ocuparam definitivamente a área. Essa ocupação foi liderada e motivada por Awá que, segundo conta, perambulava em busca da área que havia sido apontada em sonho por sua falecida mãe, onde fundaria uma aldeia (DANAGA, 2012; 2016a).

As famílias guarani mbya que vivem na aldeia vieram de diferentes lugares de uma região que compreende os estados de São Paulo, Rio de Janeiro e Paraná. Já os Tupi Guarani, vieram da aldeia Bananal, em Peruíbe/SP, conhecida como a aldeia mãe dos Tupi Guarani do litoral paulista (DANAGA, 2016b). A menção aos Tupi Guarani, grafado assim, sem o uso do hífen, refere-se à autodenominação requerida por essas famílias, antes reconhecidas pela literatura como Guarani Nhandeva. Os Tupi Guarani se definem como resultado de encontros entre os antigos Tupi da costa brasileira (Tupiniquins e Tupinambás) e os Guarani Mbya, que chegaram na região durante as migrações em busca da Ywy Marãe'y, a Terra sem Males. Explicitam, portanto, que são fruto do que costumam chamar de mistura, e não excluem os não indígenas deste processo. Reconhecem-se como "pessoas misturadas", não obstante, seus discursos denotam uma face positivada dessa mistura não compreendida, jamais, como fusão. ${ }^{6}$

Feitos esses esclarecimentos, retorno para a etnografia. O que pretendo descrever adiante aconteceu na ocasião em que estive na Ywyty Guaçu para a realização do campo do doutorado, no ano de 2014. Nesse período, demandava atenção dos Tupi Guarani um envolvimento com as questões de melhoria no campo da saúde indígena. A nossa luta hoje é essa daí, explicava-me o cacique. Ele e os outros homens da aldeia haviam chegado recentemente de uma viagem feita para Curitiba/PR, que tinha por finalidade conseguir soluções para alguns impasses da política de saúde indígena.

Depois que a Ywyty Guaçu foi identificada pela Funai como uma Terra Indígena no ano de 2003, além da construção da escola, um Posto de Saúde foi criado com a finalidade de receber visitas médicas (ao menos uma vez por semana) para prestar atendimento aos moradores da aldeia. No período anterior à identificação, a Fundação Nacional de Saúde (FUNASA), disponibilizava uma enfermeira que realizava uma visita semanal à aldeia e um médico que o fazia mensalmente. A equipe que promovia ações na área da saúde na aldeia (médica, enfermeira e dentista) era contratada por uma instituição conveniada à FUNASA, a Associação Rondon Brasil7. Além dos especialistas citados, havia dois Agentes de Saúde (AS) e um motorista.

Em outubro de 2010, a criação da Secretaria Especial de Saúde Indígena (SESAI), órgão vinculado ao Ministério da Saúde, responsável por gerir a Política Nacional de Atenção à Saúde dos Povos Indígenas e todo o processo de gestão do

6 Tupi Guarani sem o hífen é a grafia dos próprios indígenas para sua autodenominação que optei por replicar em meus trabalhos. Quanto a mistura, trata-se de outro termo que, mesmo que enunciado em português, merece ser melhor analisado sob o risco de incorrer no erro de tomar o termo por substancializações ou essencializações. A noção de pessoa calcada na ideia de mistura enquanto um enunciado relacional intrínseco da pessoa tupi guarani, dialoga com a produção recente da antropologia no campo da "contramestiçagem" (Goldman, 2015) e da-_.antimestiçagem" (Kelly, 2016).

7 A Associação Rondon Brasil foi fundada em 12/07/1999 para desenvolver ações de Prevenção de Doenças, Promoção e Recuperação de Saúde entre as populações indígenas nos Estados de São Paulo, Rio de Janeiro, Paraná, Santa Catarina, Rio Grande do Sul e Tocantins (desde 2006). Instituição reconhecida como Entidade de Utilidade Pública Municipal e Estadual e também como Organização da Sociedade Civil de Interesse Público. Informações obtidas no site http://www.rondonbrasil.org.br/index.asp. 
Subsistema de Atenção à Saúde Indígena (SASI), no âmbito do Sistema Único de Saúde (SUS), gerou grande insatisfação entre as lideranças das aldeias no litoral paulista. O novo órgão passou a gerenciar o Departamento de Saúde Indígena da Fundação Nacional de Saúde (FUNASA), que antes era responsável pelas ações de saúde, pela aquisição de insumos, apoio logístico, licitações e contratos. O saneamento básico e ambiental das áreas indígenas agora também fica a cargo da SESAI.

As novas políticas de gestão da saúde indígena, assumidas a partir da criação da SESAI, trouxeram descontentamento. Durante os períodos em que estive em campo, observei que eram raras as visitas da equipe da saúde na aldeia. O tratamento dentário era realizado somente fora dela, que não recebia mais a visita do dentista. Também não havia a caminhonete, que antes ficava disponível. Um agente de saúde e o motorista tinham sido dispensados de suas funções em demissões injustificadas, segundo relatam. Conforme dito anteriormente, quando cheguei à aldeia, muitos estavam em Curitiba, na sede do Distrito Sanitário Especial Indígena (DSEI) do Litoral Sul, que assiste às comunidades indígenas dos estados do RJ, SP, PR, SC e RS, exatamente para protestar contra algumas ações da SESAI. Foram até Curitiba com veículos próprios, na tentativa de obter um diálogo com o então chefe do DSEI do Litoral Sul. Após uma viagem de mais de mil quilômetros, ao chegarem, foram informados que o departamento de saúde indígena permaneceria fechado por uma semana, até que o coordenador do DSEI retornasse de uma viagem a Brasília. Diante disso, decidiram acampar em frente ao núcleo do Ministério da Saúde, no centro de Curitiba, com a promessa de saírem somente quando fossem ouvidos, já que, como me explicou Awá, havia uma reunião marcada há quatro meses e era inaceitável tal omissão por parte do departamento de saúde indígena. Mesmo após o período em que estive em campo, durante o qual foram realizadas as duas viagens a Curitiba, soube que as idas até a coordenação do DSEI continuaram, sempre em busca de atendimento para reivindicações feitas anteriormente e solicitando novas demandas na área da saúde.

Em todas as terças-feiras, os moradores da Ywyty Guaçu esperavam a visita da equipe médica responsável pelo atendimento na área da saúde. Inúmeras vezes esperaram em vão. Sentavam-se próximos ao Postinho, lugar do atendimento, e ficavam na expectativa. Em uma das vezes em que aguardavam - e isso foi logo após uma viagem à Curitiba - o cacique manifestou que talvez a equipe não viesse por sentir medo da presença dele na aldeia. Será que eles estão com medo que o cacique tá aqui? Novamente ninguém apareceu. Entre idas e vindas à capital paranaense, permaneciam assim na espera da visita da equipe e da recontratação do motorista e do agente de saúde, conforme prometido em reunião com membros da SESAI.

Depois de meses sem ir à aldeia, a equipe da saúde apareceu. Naquele dia, ao acordar, notei que havia um clima de tensão na aldeia. Disseram-me que o cacique havia convocado todos para uma reunião na $o c a^{8}$. Já sabiam que a equipe faria o atendimento na área. Awá, sem maiores explicações, pediu para que todos aguardassem em silêncio. Ninguém sabia o que ele iria dizer ou fazer. Seus filhos estavam apreensivos, um deles chegou a me dizer que estava preocupado, pois o pai não era homem para brincadeira e levava a luta muito a sério. Assim que o médico, a enfermeira e o motorista chegaram na aldeia, o cacique solicitou que eles fossem até a oca. Permaneciam ali sentados, aguardando a fala do cacique, que nada dizia, só observava e esperava todos se acomodarem. Após alguns minutos de um tenso silêncio, Awá se levantou na direção do médico da equipe e

${ }^{8}$ Nome pelo qual se referem a opy guaçu (casa de rezas). 
sugeriu que ele se apresentasse para a aldeia, tratava-se de um profissional novo que ainda não tinha prestado muitos serviços naquele lugar. $\mathrm{O}$ médico levantouse, respirou fundo, ergueu a cabeça, olhou para todos e assim o fez. Iniciou dizendo seu nome e que se sentia alegre por poder iniciar um trabalho junto àquele grupo. Contou sobre seu trabalho aos finais de semana em um Posto de Saúde próximo da aldeia, onde já havia atendido alguns indígenas. Mostrou reconhecer algumas pessoas que já haviam buscado atendimento lá e revelou seu anseio em continuar atuando profissionalmente entre eles. Quando o médico concluiu sua fala, Awá se levantou e disse: Então você pode pegar as suas coisas e ir embora daqui, que você não serve para trabalhar com índio. Foram médico, enfermeira e motorista a pé em direção à saída do local (o carro da SESAI, usado pela equipe para a ida até a aldeia, ficou retido). Não demorou muito para que duas viaturas da Polícia Militar (PM) chegassem. Awá convidou os policiais a entrarem na oca e explicou o motivo de sua atitude, contou sobre as dificuldades que os indígenas vêm enfrentando na aplicabilidade de seus direitos e sobre suas viagens até Curitiba. Os policiais o orientaram a ir para delegacia registrar um boletim de ocorrência. O cacique respondeu negativamente. O senhor que me desculpe, mas eu não dialogo com a PM, se quiserem resolver isso, que venham até aqui. Minha conversa não é com a PM.

Horas mais tarde, os policiais retornaram à aldeia para verificar se haviam falado com a procuradora que acompanhava o caso em Curitiba. Informaram aos policiais que conseguiram contato com a procuradora do município de Caraguatatuba e que evidenciaram o desejo deles no cumprimento do que fora acordado em Curitiba e que estava registrado em documento. $\mathrm{O}$ carro apreendido ficou meses parado no mesmo local, até que algum indicativo de resolução fosse dado ao caso.

Posteriormente, Awá me explicou que o que esperava do médico era ao menos um telefonema para mostrar preocupação com as pessoas da aldeia e esclarecer o motivo pelo qual não estava prestando o atendimento. Informou que é desse modo que se trabalha entre indígenas. É um compromisso, mais do que um serviço, disse. É assim, o índio gosta de ver as pessoas lutando junto com ele.

Nos dias seguintes, ele passou parte do tempo em um processo de articulação na convocação de lideranças para uma nova reunião que gostaria de realizar, outra vez em Curitiba. Fez ligações para o Ministério Público e noticiou aos promotores que a situação não havia melhorado. Diante da ausência de mudanças e do não cumprimento das promessas, insistia em ir até Curitiba novamente para fazer pressão no responsável. Dizia que o cenário não era mais conversa, mas para atitudes mais extremas, como o pedido de afastamento ou renúncia do cargo de coordenador da SESAI. Não queremos mais conversa com ele não, o negócio não é mais conversar, é pedir a cabeça dele agora!

Esse é um exemplo do que definem como luta, do modo de fazer política tupi guarani. Uma luta que Awá (e muitas outras lideranças, em diversos lugares) vem operando no contato com o mundo dos não indígenas e com suas políticas tão assimétricas. Conforme enfatiza o cacique, uma luta antiga e constante, que não termina e nem começa quando se consegue a terra.

Há registros de que, em 2001, realizaram um protesto em busca de melhorias nas condições de saneamento. Durante o ato, seis funcionários da FUNASA permaneceram retidos por mais de 5 horas na aldeia. Em maio de 2009, com as questões da saúde indígena ainda sob o comando da FUNASA, um grupo de cerca de cem índios realizou uma ocupação da coordenação regional do órgão no centro de São Paulo. O grupo reivindicava melhorias no atendimento médico das aldeias 
e reposição de veículos, considerados sucateados. Também era requerido pelo grupo que o então coordenador da FUNASA em São Paulo fosse demitido de seu cargo. Ele e outros funcionários foram retidos no prédio da FUNASA durante a ocupação. Em reportagem, o grupo afirmou que só aceitaria deixar o prédio após a demissão do coordenador, que foi acusado de ser negligente e de realizar uma má administração. Em três anos, ele nunca fez uma visita (às aldeias). Tem criança morrendo com água contaminada, faltam remédios, o saneamento básico é ruim, declarou Awá em entrevista ao jornal. Awá estava na liderança do movimento, que era composto por outros caciques de diversas terras indígenas do Litoral Norte e outras do Litoral Sul e Vale do Paraíba. Seu nome se encontra em todas as reportagens dos jornais locais que fizeram a cobertura do movimento. "Não deixaremos o prédio enquanto essa situação não se resolver. Estamos completamente desamparados pela Funasa e vamos lutar até o fim, afirmou o cacique Awa, da etnia tupi-guarani, durante a ocupação".

Em julho de 2013, com a saúde indígena gerida pela SESAI e não mais pela FUNASA, Awá convocou nova reunião com outras lideranças para conversarem sobre o atendimento à Saúde Indígena no estado de São Paulo e decidiram iniciar um novo movimento em busca de melhorias e direitos não atendidos. O motivo apresentado pelo cacique para convocação da reunião é a demanda de diálogo sobre o atendimento à Saúde Indígena no estado de São Paulo. Consta em ata de reunião realizada em maio do mesmo ano que, no dia 13 daquele mês, algumas lideranças promoveram o fechamento do escritório local da SESAI em São Paulo e que o ato culminou em uma nova reunião no Ministério Público Federal. Nessa reunião com o Procurador da República, ficou marcada uma outra reunião, dessa vez com a participação do coordenador do DSEI Litoral Sul e com o chefe de gabinete do secretário de Saúde Indígena, que ocorreu no mesmo mês, no Auditório da Procuradoria da República em São Paulo, e teve como pauta o levantamento das prioridades de todas as aldeias que estavam presentes. Os principais pontos levantados, de acordo com a ata, foram críticas à paralisação dos convênios responsáveis pelo fornecimento de medicamentos, falta de manutenção de viaturas, vale-transporte, contratação de hospedagem e alimentação para indígenas em trânsito quando em tratamento de saúde, ausência de clínica médica especializada e assistência funeral. Criticaram, ainda, a redução da carga horária da equipe médica sem diálogo prévio com as comunidades, direito dos indígenas, conforme a Constituição Federal de 1988 e a Convenção 169 da Organização Internacional do Trabalho (OIT). Requereram capacitação dos servidores indígenas para as ações dos Agentes de Saúde, Saneamento e Bucal e garantia de atendimento de saúde para os indígenas que vivem nas cidades.

Menos de um mês após essa reunião, os indígenas ocuparam o Polo Base da SESAI, no município de Peruíbe/SP, reivindicando o atendimento às demandas ajustadas nas reuniões ocorridas anteriormente com o Coordenador do DSEI Litoral Sul. Na ocasião, os indígenas alegaram que os compromissos não estavam sendo cumpridos e que ainda permaneciam sem o atendimento das equipes de saúde nas aldeias. Funcionários do polo foram detidos na tentativa de assegurar o diálogo com o Coordenador do DSEI, que marcou reunião com o grupo e não apareceu. Quase um ano depois, quando cheguei à aldeia para realizar minhas pesquisas, o assunto ainda não estava resolvido e, mais uma vez, partiram para uma nova ocupação da SESAI em Curitiba.

Discorri sobre essas ações no campo da saúde porque elas são parte da luta travada na política feita com os não indígenas. E, ainda, porque foram questões que estiveram marcadamente presentes nos momentos em que estive em campo. 
Dialogar com os não indígenas por melhorias na saúde é apenas um fragmento dessa luta sobre a qual fala Awá, componente de seu modo de fazer política, , não o único, evidentemente. Da mesma maneira, a luta acontece por meio e através da terra, como afirmou em outros momentos. Dá-se de modo ora mais, ora menos aguerrido. ${ }^{9}$ Expulsar pessoas da aldeia e manter carros e pessoas retidos na tentativa de ver atendidas as reivindicações, são ações que revelam um modo de lutar, uma forma possível de ser notado pela política dos não índios. É assim que os Tupi Guarani fazem política. É dessa forma que Awá define o que é fazer política com os não indígenas, lutando.

As "cenas" de expulsão do médico, de funcionários da Funai, a retenção de carros e pessoas, tudo isso, é a potência que a luta assume enquanto forma de se fazer política com os não indígenas na Ywyty Guaçu. Para Awá, é esse o meio pelo qual se deve fazer política, é assim que ele reafirma seu perfil de liderança "dentro" e "fora" da aldeia, mostrando que liderança é um efeito da relação que existe entre a autoridade e a alteridade. A luta concebida como potência viabilizada pela "performance tupi guarani" é parte do que afirmam ser sua disposição guerreira. ${ }^{10}$

Isso reforça a necessidade de reconhecer que a alteridade também é diversa. Há muitos tipos de brancos, não indígenas ou jurua, como preferem chamar os Tupi Guarani. Existe uma pluralidade desse tipo de gente e de relações que podem ser firmadas. São inúmeras as possibilidades de alianças que ocorrem com outros tipos de gente. Ademais, toda luta consiste, antes, do encontro. Dele, podem emergir conflitos ou, ainda, ligações de compromisso e engajamento. A luta é sempre contra o inimigo e a favor do amigo e, nos mundos ameríndios, são muitos os inimigos e amigos. Eles podem estar em toda parte.

Assim, o fazer política como luta, pode se dar através do estabelecimento de uma rede com outros tipos "melhores" de brancos, instaurando uma forma de uma "aliança afetiva", como, por exemplo, constatou Ailton Krenak. Ao criar laços com brancos "melhores" (entidades e pessoas que trabalham e lutam junto com os indígenas, pela causa indígena) funda-se uma rede que não cessa de gerar potência ao movimento, seja ele no interior de um país ou fora dele, e amplia as possibilidades de vocalização. Nas palavras de Ailton Krenak:

\footnotetext{
Eu já experimentava a atuação em rede, porque sabia que estava no Brasil, no Mato Grosso, mas tinha um cara na Holanda que não falava português, nem eu holandês, mas que sabia que eu estava fazendo aquela trajetória e ele estava divulgando aquilo. Eu tinha certeza que ele estava fazendo isso, e que aquilo resultava em potência para o que eu estava fazendo. Isso é rede. [...] E não tinha contrato, protocolo. Era uma relação de confiança, que eu chamei de alianças afetivas. (KRENAK, 2015, p. 251)
}

\footnotetext{
9 A divulgação da aldeia por meio de imagens veiculadas nas redes sociais, reportagens, vídeos e outras mídias é também um jeito de dialogar com os não indígenas, um modo de operar político. (DANAGA, 2012b).

${ }^{10}$ A assertividade na forma de falar e agir revelam uma "performance tupi guarani", do mesmo modo para a qual sinalizou Kelly (2005), ao falar de uma "performance yanomami", igualmente acionada em um contexto de reivindicação e protesto no âmbito da saúde indígena. A "performance tupi guarani", de caráter mais aguerrido é, por exemplo, contrastada com o que denominam jeito calmo dos Guarani Mbya.
} 


\section{Política em outros termos}

Até agora, falei dos modos de fazer políticas dos Tupi Guarani, mostrando que a luta pode expressar essas relações. Há outros conceitos que não são transparentes nas relações entre os Tupi Guarani, como por exemplo, o de organização.

Se luta parece ser da ordem do fazer política com os não indígenas, pois quando se fala com eles, geralmente, se conversa com os inimigos, ao operar políticas entre os parentes, no cotidiano da aldeia, o termo organização é bastante acionado.

Como acredito ter feito com o conceito de luta, pretendo "levar a sério o português" dos Tupi Guarani e pensar nos usos da palavra organização, um conceito que pode contribuir para o entendimento dos agenciamentos na Ywyty Guaçu. Vou tratar do conceito de organização tal qual meus interlocutores, para me referir ao fazer política, agora pensando nas relações internas da aldeia. Lembrando que, mesmo nas relações internas da aldeia, há uma convivência marcada por diferentes tipos de gente: os não indígenas e os Guarani Mbya que residem na Ywyty Guaçu, o que matiza os contornos das possibilidades de se pensar em termos de "dentro" ou "fora".

A ação, ato ou efeito de organizar algo é para nós, não índios, o significado da palavra organização. Entendemos que organização é uma expressão da mesma ordem que sociedade, organismo ou instituição e que, portanto, fazer política é uma forma de e para organização. Parece estarmos de acordo, nós e os Tupi Guarani, quando pensamos que política é organização, só não compactuamos ao pensar o contrário, que toda organização é política. Para os Tupi Guarani, organização é ao mesmo tempo beleza e caos, ordem e desordem. Para se fazer a política como organização, é necessário que, antes de tudo, as coisas estejam desorganizadas. A produção de uma desordem constante é o que permite a busca da ordem.

Mais uma vez, desde Clastres (2003), aprendemos que uma autoridade política forte entre povos Tupi-Guarani pode romper com a organização social vigente e estabelecer o caos. É latente a possibilidade da socialidade em montar-se e desmontar-se constantemente. ${ }^{11} \mathrm{E}$, quando isso acontece, é preciso buscar modos de se reverter a situação do caos e restabelecer a ordem.

Awá foi pivô na condução de um grupo de pessoas até a Ywyty Guaçu que, nos dias atuais, basicamente, é formada por seus filhos e suas respectivas famílias, e algumas famílias guarani mbya que, geralmente, não fixam residência, salvo algumas exceções. A existência dessas famílias mbya na aldeia implica uma convivência nem sempre esvaziada de conflitos. Ainda que convivam em um mesmo espaço, sob a mesma liderança e que sejam bem diferentes em muitos aspectos, a política executada para orquestrar essas diferenças não é a mesma da ordem da luta.

Lembrando, mais uma vez, a respeito das inúmeras possibilidades que os indígenas trazem para se pensar não só o fazer política, mas uma série de outras coisas, a partir de seus próprios termos, de seus próprios modos de conceber e praticar a política. Como se referiu Perrone-Moisés (2011, p. 868): “Entre Estado e não Estado, há lugar para toda sorte de dosagens, que as políticas ameríndias exploram".

\footnotetext{
11 Trata-se de uma socialidade que se faz e se desfaz o tempo todo, através de processos sociais que se produzem e se desarticulam ao mesmo tempo. Como notou alhures Santos-Granero (2000), uma socialidade que a todo instante busca um recomeço e que remete à ideia presente no mito de Sísifo, o personagem da mitologia grega que realizava a repetitiva tarefa de empurrar uma pedra montanha acima, e que nunca concretizava sua ação, pois a pedra rolava cada vez que ele se aproximava do cume, obrigando-o a reiniciar a missão.
} 
A política feita com as pessoas na aldeia não é encarada como uma guerra, mas como uma possibilidade cotidiana de diálogo, como perspectiva de fortalecimento da cultura, como enfatizam. Nesse contexto, das relações rotineiras entre as famílias tupi e as mbya, entre os indígenas e os não indígenas que vivem na aldeia, o fazer política é enunciado como organização. Nós somos diferentes, mas o sofrimento é o mesmo, então a gente precisa se organizar aqui dentro.

Os procedimentos que esse fazer política, entendido por organização, assumem, vão desde organizar literalmente o espaço, mantendo-o bem arrumado e limpo, até organizar condutas, como o respeito à liderança, o falar na língua, a educação das crianças, a frequência com que se vai a opy, entre outros. Organizam-se coisas, lugares e pessoas. Para todas essas ações que se conectam com uma política feita no e para o interior da vida na aldeia, Awá usa o termo organização. Ele diz: Vamos nos organizar [...]. Temos que nos organizar [...]. E preciso organizar as coisas aqui dentro.

Decorre disso um desejo explícito da liderança em estimular as ações. Um tipo de ação que visa atrair e guiar as pessoas, análoga à ação do tenotã -mõ Araweté, do qual fala Viveiros de Castro (1986). Entre os Araweté, o tenotã-mõ é aquele que segue à frente, que principia e que abre o caminho para os demais.

Essa palavra designa o termo inicial de uma série: o primogênito de um grupo de irmãos, o pai em relação ao filho, o homem que encabeça uma fila indiana na mata, a família que primeiro sai da aldeia para uma excursão na estação chuvosa. O líder araweté é assim o que começa, não o que comanda; é o que segue na frente, não o que fica no meio. Toda e qualquer empresa coletiva supõe um Tenotã-mõ. Nada começa se não houver alguém em particular que comece. Mas entre o começar do Tenotã-mõ, já em si algo relutante, e o prosseguir dos demais, sempre é posto um intervalo, vago mas essencial: a ação inauguradora é respondida como se fosse um pólo de contágio, não uma autorização. (VIVEIROS DE CASTRO, 1986, p. 302)

O tenotã-mõ é aquele que propõe. É ele quem instiga as pessoas às ações coletivas, é a liderança necessária para organizar coletivamente um grupo que, a depender apenas de si, vive no caos, sem iniciar atividades coletivas. O tenotãmõ é o ímpeto da aldeia e não necessariamente o chefe. Awá é liderança na Ywyty Guaçu, porém, nem sempre consegue agir como um tenotã-mõ o que o deixa descontente. Pra tá organizando parece que tem que tá puxando pelo braço, senão não vai.

Muitas reuniões acontecem para discutir a organização. Seja a organização entendida como arrumação, limpeza ou, ainda, a organização como ação de liderança ao organizar coisas e gentes.

Parece que a ideia é produzir beleza o tempo todo. É criar um efeito espacial (ou especial?) que se realiza na imagem e na beleza da aldeia. A imagem da aldeia é algo que deve ser zelado e divulgado. Por isso fotografam, filmam e postam nas redes sociais. Dizem sempre que a Ywyty Guaçu é uma aldeia muito admirada entre os indígenas e os não indígenas, exatamente por ser assim, tão organizada e bonita. E esse ideal de organização, tão requerido por Awá, vai além da questão estética de ter uma aldeia bonita: instaura-se, ainda, no comportamento das pessoas. Apesar de reprovar os hábitos de organização dos Mbya e seus asseios diferentes dos Tupi, ressaltam que os Mbya têm outra forma de organização, que é muito harmonizada e ordem do cultural, como dizem. Afirmam que os Mbya são bem organizados. Eles têm parteiras, a título de exemplo, coisa que os Tupi desconheciam a muito tempo, segundo contam. Os Mbya preservam a língua e a cultura e são organizados nesse ponto. Consideram que falta aos Tupi Guarani seguirem o exemplo de se organizarem na cultura. 
E mesmo que tudo parecesse estar sistematicamente estruturado, de quando em quando estavam lá, todos reunidos na oca, para ouvir o cacique falar da necessidade de organização. Vocês têm que se acertar, têm que estar colaborando, têm que se organizar. Cria-se uma impressão de desordem perpétua que permite a imposição constante de ordem, ratificando o seu domínio dentro do grupo e, assim, instituindo uma dada socialidade. "Chefe é quem sabe organizar o pessoal”, disseram os interlocutores de Perrone-Moisés (2011, p. 875).

Manter a aldeia organizada é, ao mesmo tempo, efetivar-se enquanto liderança, caso contrário, surge a ameaça de abandonar a aldeia, como já o fez por uma vez. Nesse caso, a ameaça de abandono parte da própria liderança em relação ao seu grupo e não do grupo em relação à liderança. De acordo com o modelo do chefe clastreano, cujo desejo de poder é constantemente mediado, se esse desejo se exacerba, o chefe é abandonado ou, no limite, morto pelo grupo (CLASTRES, 2003).

Para Awá, essa é a sua função política enquanto liderança, que não deve ter sua potência valorizada apenas diante dos períodos de guerra, isto é, requerida em momentos de negociações da política como luta. ${ }^{12}$ A liderança está, também, atrelada à organização das atividades e obrigações cotidianas na aldeia onde é o cacique. Se é requerida sua ação com os não indígenas, nos momentos de luta, a contrapartida deve ser o respeito e a colaboração das pessoas que vivem dentro da aldeia. É a dádiva e a dívida como categorias cíclicas que regem muitas das relações entre os chefes e seus grupos.

\section{Considerações Finais}

Busquei argumentar que luta é uma palavra que aparece com frequência nas relações entre indígenas e não indígenas, um conceito que marca o caráter quase sempre combativo dessas relações. Do mesmo modo, para o contexto etnográfico especificado nesse texto, aparece o conceito de organização, para nomear ações que são como a luta, porém com outras particularidades. A ideia foi, sobretudo, observar como os Tupi Guarani em suas relações com múltiplos mundos (dos não indígenas e dos Guarani Mbya) criam discursos que modulam essas ações. Atentei para os estilos narrativos que constituem um tipo específico de liderança, pelas experiências de Awá.

Nesse sentido, procurei mostrar como categorias aparentemente dadas são acionadas em contextos políticos nos diálogos desses múltiplos mundos, seja com os não índios ou com os Guarani Mbya. O conceito de luta foi fundamental para entender partes dessas relações e revelou um modo tupi guarani singular de fazer política. Estar na luta, como vimos, é uma maneira tupi guarani de agir entre mundos, mesmo que essa luta esteja sempre em transformação e com outros contornos como da guerra. Num mundo tão diferente, mas que opera pela mesma língua, há que se ter cautela diante das (im) possibilidades das "traduções”. É preciso tentar controlar ao máximos os equívocos, pois certamente existirão. Luta é relação, um modo de relacionar-se com uma política de outro mundo: o dos não indígenas. Não é uma resposta à política deles, mas um modo de se relacionar.

\footnotetext{
${ }_{12}$ Nesse caso, o papel desempenhado por Awá pode remeter ao que Perrone-Moisés (2011) chamou de "chefes de guerra", isto é, lideranças dotadas de potência nos períodos marcados pela guerra. Contudo, Perrone-Moisés (2011) destaca que uma mesma pessoa pode assumir, embora não concomitantemente, tanto o papel do "chefe de guerra", como o papel do "chefe de paz", aquele mais ligado ao chefe sem poder clastreano, que são os chefes só no nome, com baixo poder de coerção. Para a autora os "chefes de paz" e os "chefes de guerra" possuem papéis diferentes que podem ser ocupados pela mesma pessoa, pelo mesmo guerreiro, mas nunca ao mesmo tempo. (PERRONE-MOISÉS, 2011).
} 
Assim, percebi que a categoria luta estava associada a contextos não indígenas, como um modo de se relacionar com o inimigo, distinto do fazer política dentro da aldeia, por exemplo. Esse fazer política para dentro, não quer dizer uma ausência de entre mundos, porque o "dentro" não é homogêneo. Há um entre em tudo. Para essa política feita na aldeia, o termo acionado era organização. E, para que as coisas estejam organizadas, em algum momento, elas precisam se desorganizar, o que garante um movimento contínuo, movimento que, aliás, é parte dos Tupi Guarani, seja na disjunção e na conjunção de coletivos ou nos movimentos que decompõem e compõem a pessoa tupi guarani, como mostraram as etnografias de Mainardi (2015) e Almeida (2016) entre as famílias tupi guarani.

Considerei os contextos enunciativos. A preocupação com aquilo que se enuncia (e com a forma como se enuncia) não ignora o fato de que a política está sempre sendo feita, independente das definições e escolhas metodológicas aqui propostas para tratar a pluralidade de modos de se fazer políticas entre os Tupi Guarani e das ações políticas tomadas especificamente pela liderança,. Trata-se de uma ação contínua, relacional e processual.

A articulação de categorias como dentro, fora, interior, exterior, luta e organização, teve como intuito diferenciar, textualmente, os modos enunciativos elicitados pelos Tupi Guarani ao fazerem tais políticas. Nesse sentido, todas essas categorias estão mútua e reciprocamente imbricadas nas ações e enunciados políticos na Ywyty Guaçu. Diferenciações que são da ordem do contexto enunciativo, pois compreendo que a política tupi guarani está sempre em movimento e não faria sentido caracterizá-la com o uso de termos estanques. Assim, quando Awá diz estamos na luta, ele está, ao mesmo tempo, organizando as pessoas. Organizar ações, coisas e pessoas é a luta diária. Se Antonio Awá diz estar na luta, isso acontece, sem dúvidas, para fazer pessoas. Do mesmo modo, se ele organiza e produz pessoas, é para que estas estejam na luta. Sua liderança é operada na política, seja ela como luta ou como organização, e a política é um fazer constante. Parece ser todo esse o esforço. Um esforço empreendido sempre na relação, ora com inimigos, ora com aliados.

Recebido em 30 de setembro de 2018.

Aprovado em 10 de abril de 2019.

\section{Referências}

ALMEIDA, Lígia Rodrigues. Estar em movimento é estar vivo. Territorialidade, pessoa e sonho entre famílias tupi guarani. 2016. Tese (Doutorado em Antropologia Social) - Universidade de São Paulo, São Paulo, 2016.

ALMEIDA, Lígia Rodrigues. Os Tupi Guarani de Barão de Antonina (SP): migração, território e identidade. 2011. Dissertação (Mestrado em Antropologia) - Universidade Federal de São Carlos, São Carlos, 2011.

ALMEIDA, Lígia. R.; DANAGA, Amanda C; MAINARDI, Camila. Um nome que faz diferença: reflexões com famílias tupi guarani. In: GALLOIS, Dominique T.; MACEDO, Valéria, M. de (Org). Nas redes Guarani: um encontro de saberes, traduções e transformações. Editora Hedra. São Paulo, 2018.

CALAVIA SÁEZ, Oscar. Autobiografia e sujeito histórico indígena, considerações preliminares. Novos Estudos - CEBRAP, n. 76, 2006. 
CALAVIA SÁEZ, Oscar. Autobiografia e liderança indígena no Brasil. Tellus, Campo Grande, v. 7, n. 12, 2007.

CLASTRES, Pierre. A sociedade contra o Estado. São Paulo: Cosac \& Naify, 2003.

DANAGA, Amanda Cristina. Os tupi, os mbya e os outros: um estudo etnográfico da aldeia renascer - Ywyty Guaçu. 2012. Dissertação (Mestrado em Antropologia) - Universidade Federal de São Carlos, 2012a.

DANAGA, Amanda Cristina. Os tupi guarani da aldeia renascer (SP): uma reflexão sobre os enunciados da mistura e os agenciamentos da "cultura". Espaço Ameríndio, Porto Alegre, v. 6, n. 2, p. 10-31, jul./dez. 2012 b.

DANAGA, Amanda Cristina. Nome e relações. A noção de mistura entre famílias tupi guarani do litoral paulista. In: DANAGA, Amanda Cristina; PEGGION, Edmundo Antonio (Org.). Povos indígenas em São Paulo: novos olhares. São Carlos: EdUFSCar, São Carlos, 2016a.

DANAGA, Amanda Cristina. Encontros, efeitos e afetos. Discursos de uma liderança tupi guarani. Tese de doutorado. PPGAS, Universidade Federal de São Carlos, 2016b.

FRANCHETTO, Bruna. Línguas ameríndias: modos e caminhos da tradução. $C a-$ dernos de Tradução, Florianópolis, v. 2, n. 30, p. 35-62, out. 2012.

GONÇALVES, Marco Antônio; MARQUES, R.; CARDOSO, Vânia Zikán (Org.). Etnobiografia: subjetivação e etnografia. Rio de Janeiro: 7 Letras, 2012.

KELLY, José, A. Notas para uma teoria do virar branco. Mana, Rio de Janeiro, v. 11, n. 1, p. 201-234, 2005.

KELLY, José A. Aprendendo sobre os diálogos cerimoniais Yanomami. Species Núcleo de antropologia especulativa, n. 1, 2015.

KOFES, S. Uma trajetória em narrativas. Campinas: Mercado de Letras, 2001.

KOFES, Suely, MANICA, Daniela. Vida \& grafias: narrativas antropológicas, entre biografia e etnografia. Rio de Janeiro: Lamparina, 2015.

KOPENAWA, Davi; ALBERT, Bruce. A queda do céu: palavras de um xamã Yanomami. São Paulo: Companhia das Letras, 2015.

KRENAK, Ailton Alves Lacerda; COHN, Sergio. Encontros. Rio de Janeiro: Azougue, 2015.

MAINARDI, Camila. Construindo proximidades e distanciamentos: etnografia da Terra Indígena Tupi Guarani Piaçaguera/SP. 2010. Dissertação (Mestrado em Antropologia) - Universidade Federal de São Carlos, São Carlos, 2010.

MAINARDI, Camila. Desfazer e refazer coletivos: o movimento tupi guarani. 2015. Tese (Doutorado em Antropologia Social) - Universidade de São Paulo, São Paulo, 2015.

OAKDALE, Suzanne. I foresee my life: the ritual performance of autobiography in an amazonian community. USA: University of Nebraska Press, 2005.

OAKDALE, Suzanne. Anchoring "the symbolic economy of alterity" with autobiography. Tipiti: Journal of the Society for the Anthropology of Lowland South America, v. 5, n. 1, p. 4, 2007.

OAKDALE, Suzanne; COURSE, Magnus. Fluent Selves: autobiography, person, and history in Lowland South America. [S. 1.]: [s. n.], 2014a. 
OAKDALE, Suzanne. Interview with Suzanne Oakdale by Rita de Cácia Oenning da Silva. Horizontes Antropológicos, Rio Grande do Sul, 2014 b.

PERRONE-MOISÉS, Beatriz; SZTUTMAN, Renato. Notícias de uma certa confederação tamoio. Mana, v.16, n. 2, 2010.

PERRONE-MOISÉS, Beatriz. Bons chefes, maus chefes, chefões: elementos de filosofia política ameríndia. Revista de Antropologia, São Paulo, v. 54, n. 2, 2011.

PERRONE-MOISÉS, Beatriz. Festa e guerra. Tese (Livre-docência em Antropologia Social) - Universidade de São Paulo, São Paulo, 2015.

SANTOS-GRANERO, Fernando. The Sisyphus Syndrome, or the struggle for coviviality in Native Amazonia. In: OVERING, Joana; PASSES, Alan (Ed.). The Anthropology of love and anger: the aesthetics of conviviality in native Amazonia. London: Routledge, 2000.

SZTUTMAN, R. Religião nômade ou germe do Estado? Pierre e Hélène Clastres diante da vertigem tupi. Novos Estudos - CEBRAP, v. 83, p. 129-157, 2009.

SZTUTMAN, Renato O profeta e o principal: a ação política ameríndia e seus personagens. São Paulo: Edusp; FAPESP , 2012.

VIVEIROS DE CASTRO, Eduardo. Araweté: os deuses canibais. Rio de Janeiro: Jorge Zahar, 1986.

VIVEIROS DE CASTRO, Eduardo. O nativo relativo. Mana, Rio de Janeiro, v. 8, n. 1, 2002.

VIVEIROS DE CASTRO, Eduardo. Perspectival anthropology and the method of controlled equivocation. Tipití: Journal of the Society for the Anthropology of Lowland South America, v. 2, n. 1, p. 1, 2004.

WAGNER, Roy. The fractal person. In: STRATHERN, Marilyn; GODELIER, Maurice (Org.). Big men and great men: personifications of power in melanesia. Cambridge: Cambridge University Press, 1991.

WAGNER, Roy. A invenção da cultura. São Paulo: Cosac Naify, 2010. 